\title{
International symposium on eco-materials processing and design (ISEPD) 2012
}

\author{
Jinlong Zhang
}

Published online: 20 November 2012

(C) Springer Science+Business Media Dordrecht 2012

The series of International Symposium on Eco-materials Processing and Design (ISEPD) conferences, which were held in China, Japan, Korea, and last year in Thailand, have become a key platform for distinguished leaders and young scientists from all over the world to exchange new scientific and technological ideas and present recent scientific findings and technological developments in terms of all aspects of environmental and eco-material-related issues.

In January 2012, the 13th ISEPD was held in Guilin, China. During the symposium, more than 30 invited technical talks were given by experts and researchers from different countries, and nearly 200 researchers including colleagues from Nagaoka University of Technology, Osaka University, Korea Institute of Materials Science, Sun Moon University, Chinese Academy of Science, Sichuan University, etc. attended and enjoyed fruitful discussion at this conference. This special issue of Research on Chemical Intermediates includes contributions from the presenters and attendees at this symposium, with the aim of covering the latest developments in "nanomaterials and environmental photocatalysis." Eleven papers were submitted for this issue, which were carefully peer-reviewed and revised for publication.

I would like to thank all of the colleagues, collaborators, staff, and students who contributed to the 2012 ISEPD and this special issue, especially Prof. Masakazu Anpo for editing this journal. I also would like to thank all the authors who submitted their research work to this issue, and all the reviewers who spent their precious time and effort reviewing the submitted manuscripts.

\footnotetext{
J. Zhang ( $\bowtie)$

Key Laboratory for Advanced Materials and Institute of Fine Chemicals, East China University of Science and Technology, 130 Meilong Road, Shanghai 200237, People's Republic of China e-mail: jlzhang@ecust.edu.cn
} 


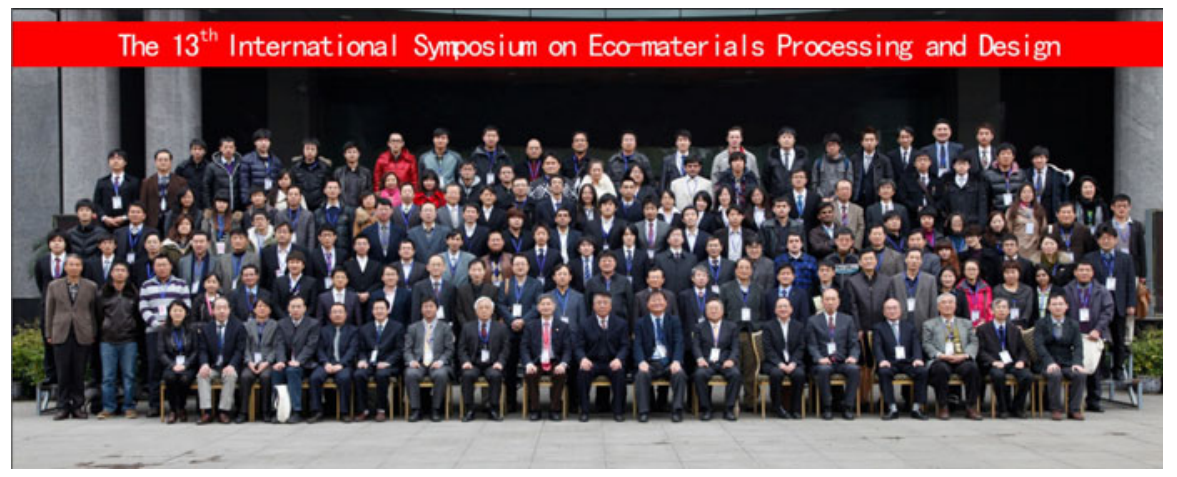

